\title{
A Fuzzy Based Evolutionary Algorithm for Solving Multiobjective Optimal Power Flow with FACTS Devices
}

\author{
R. Vanitha ${ }^{1}$ and J. Baskaran ${ }^{2}$ \\ ${ }^{1}$ Faculty of Electrical and Electronics, Sathyabama University, Chennai 600119, India \\ ${ }^{2}$ Department of Electrical and Electronics Engineering, Adhiparasakthi Engineering College, Melmaruvathur 603319, India \\ Correspondence should be addressed to R. Vanitha; vanitha.eee@sathyabamauniversity.ac.in
}

Received 31 March 2015; Revised 12 July 2015; Accepted 15 July 2015

Academic Editor: Juan F. San-Juan

Copyright (C) 2015 R. Vanitha and J. Baskaran. This is an open access article distributed under the Creative Commons Attribution License, which permits unrestricted use, distribution, and reproduction in any medium, provided the original work is properly cited.

A new Fuzzy Differential Evolution (FDE) algorithm is proposed for solving multiobjective optimal power flow with FACTS devices. This new optimization technique combines the advantages of Weighted Additive Fuzzy Goal Programming (WAFGP) and Differential Evolution (DE) in enhancing the capacity, stability, and security of the power system. As the weights used in WAFGP would have a significant impact on the operational and economical enhancements achieved in the optimization, they are optimized using evolutionary DE algorithm. This provides a way for exploring a balanced solution for a multiobjective problem without sacrificing any individual objective's uniqueness and priority. The multiple objectives considered are maximizing the loadability condition of the power system with minimum system real power loss and minimum installation cost of the FACTS devices. Indian utility Neyveli Thermal Power Station (NTPS) 23 bus system is used to test the proposed algorithm using multiple FACTS devices. The results compared with that of DE based fuzzy goal programming (FGP) demonstrates that DE based WAFGP algorithm not only provides a balanced optimal solution for all objectives but also provides the best economical solution.

\section{Introduction}

The ever-increasing demand of electric power and deregulation norms followed in certain countries create a heavy traffic, and thereby straining an existing power network. Maintaining the stability and security of power network becomes the foremost challenge for the power suppliers.

FACTS devices are power electronic devices that can be inserted in existing power network at desired location without altering the existing network. They provide required transmission line impedance, real power, and reactive power, maintain the voltage levels at buses which in turn increases the load carrying capacity of transmission network, reduces real and reactive power losses, and maintains voltage stability in the overall power network [1].

The optimal location and sizing of FACTS controllers in a power network are done for better utilization of these devices in an economical way. Several conventional and intelligent natural inspired algorithms are available in obtaining a global optimal solution for a single objective optimization [2-6].
When more than one objective is considered for optimization, the problem turns out into a multiobjective optimization yielding Pareto optimal solutions. The fuzzy concept is one of the most popular methodology that can be combined with any conventional/intelligent techniques to bring out the best global optimal solution from pareto optimal solutions.

Zadeh was the first to introduce the concept of fuzzy set theory in the year 1965 [7]. Narasimhan has illustrated the application of fuzzy subsets concepts to fuzzy goal programming in 1980 [8]. Tiwari et al. have formulated an additive model to solve fuzzy goal programming in 1987 [9]. This model is mostly suited for multiobjective problems where objectives have different levels of importance. Many researchers have used fuzzy technique with other optimization methods to solve multiobjective optimal power flow problems in an effective manner.

Rosehart et al. have combined interior point methods with goal programming in optimizing active and reactive power dispatch while maximizing voltage security in power systems in 2003. In 2011, Hazra and Sinha have presented 
a multiobjective particle swarm optimization method for minimizing generation cost and environmental pollution simultaneously. Liang et al. (2011) have presented a fuzzy based hybrid particle swarm optimization (PSO) approach in minimizing fuel cost, total emission, and total real power loss [10-12].

In 2011, Sivasubramani and Swarup have proposed multiobjective harmony search (MOHS) algorithm and $\mathrm{He}$ et al., in 2013, have used Artificial Bee Colony (ABC) algorithm to solve multiobjective OPF. Azizipanah-Abarghooee et al. have presented modified Shuffled frog-leaping algorithm (SFLA) in solving multiobjectives like reducing generation cost, decreasing transmission loss, improving voltage stability index, and power system security in 2014 [13-15]. In all the above papers, fuzzy membership is used to choose a comprise solution from the set of Pareto optimal solutions. In this paper, maximization and minimization goals for each objective in multiobjective OPF are determined using $\mathrm{DE}$ algorithm and are converted to fuzzy goals using fuzzy membership values. Each fuzzy goal is assigned with a weight and all fuzzy goals are combined together to frame the Weighted Additive Fuzzy Goal model. Taking the importance of each individual objective into consideration, the weights for each objective in multiobjective OPF is optimized using DE algorithm.

This paper is organized into seven sections. Section 1 provides an introduction. Section 2 presents the implementation of mathematical modelling of FACTS devices in power system network. Section 3 formulates this study's problem. Section 4 describes the proposed FDE approach in detail for optimal location of FACTS in a multiobjective optimization. Section 5 presents and discusses the results, and Section 6 concludes the benefits of this study.

\section{Implementation of Facts Devices in Power System Network}

The generalized real and reactive power flow equations for a bus " $i$ " without any FACTS devices connected in a power system can be written as:

$$
\begin{aligned}
P_{i} & =\sum_{j=1}^{n b r}\left|V_{i}\right|\left|V_{j}\right|\left|Y_{i j}\right| \cos \left(\delta_{i}-\delta_{j}-\theta_{i j}\right), \\
Q_{i} & =\sum_{j=1}^{n b r}\left|V_{i}\right|\left|V_{j}\right|\left|Y_{i j}\right| \sin \left(\delta_{i}-\delta_{j}-\theta_{i j}\right),
\end{aligned}
$$

where nbr is the total number of transmission line branches in a power system; $\theta$ and $Y$ are the angle and magnitude of bus admittance elements; $|V|$ and $\delta$ are magnitude and phase angle of bus voltages; $P$ and $Q$ are real and reactive powers of the buses.

The introduction of FACTS devices in the power systems makes a significant change in the power flow equations that depends on the mathematical model of FACTS devices.

2.1. Thyristor Controlled Series Capacitor. TCSC is a series compensated thyristor controlled device that is comprised

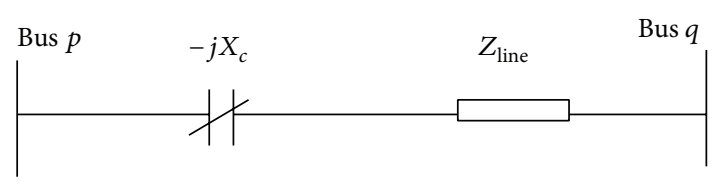

FIGURE 1: Equivalent circuit of TCSC.

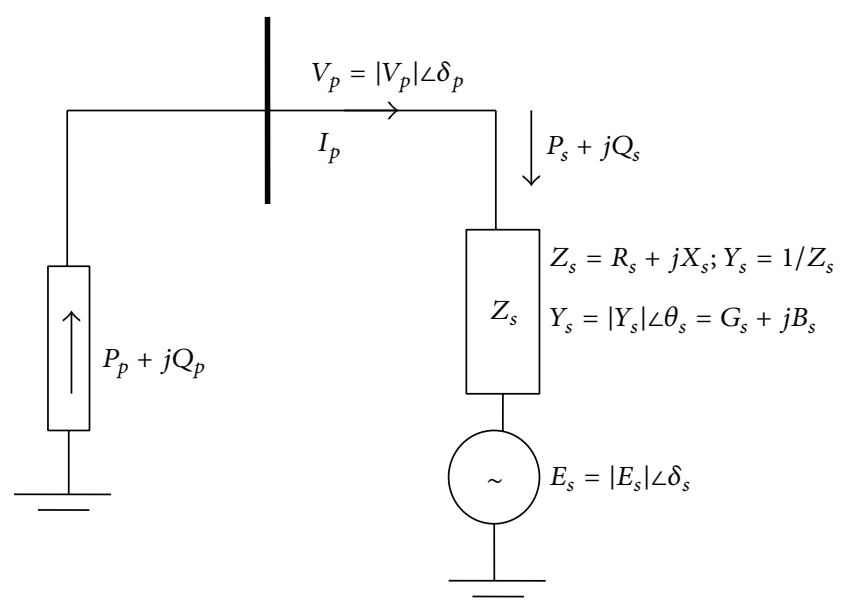

Figure 2: Power injection model of STATCOM.

of a capacitor in parallel with a TCR. Figure 1 depicts the equivalent circuit of a TCSC. In this model, the desired transmission line impedance can be achieved for smoother reactive power control by controlling the TCSC both in inductive and capacitive modes.

The transmission line reactance to which the TCSC is connected is only altered as shown in (2) that in turn makes the significant change in the power flows [16]:

$$
X_{\text {line }}=X_{\text {line }}+X_{c}
$$

where

$$
r_{c}^{\min } * X_{\text {line }} \leq X_{c} \leq r_{c}^{\max } * X_{\text {line }}
$$

$r_{c}$ is the amount of compensation that can be provided by the TCSC in inductive and capacitive mode.

2.2. STATCOM. STATCOM is a shunt-connected device that is comprised of a voltage source converter fed from a capacitor or a constant DC source. It can independently control real and reactive power with the power system. Reactive power can be supplied or absorbed by varying the magnitude of voltage and real power can be controlled by varying the phase angle of the voltage with respect to the bus voltage to which it is connected. The power injection model of STATCOM is shown in Figure 2 [17]. In this model, the STATCOM is considered as a voltage source in series with an impedance $Z_{s}$. 


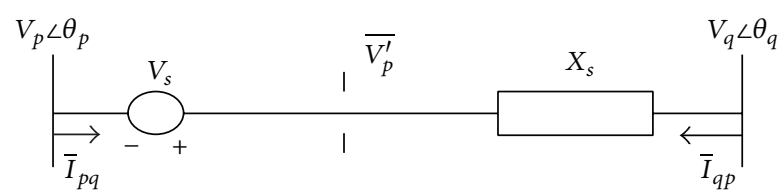

FIGURE 3: Equivalent circuit of series connected VSC.

The real power and reactive power at bus $p$ to which the STATCOM is connected get altered with the addition of injected real and reactive powers of STATCOM as

$$
\begin{gathered}
P_{p}=P_{s}+\sum_{q=1}^{\mathrm{nb}}\left|V_{p}\right|\left|V_{q}\right|\left|Y_{p q}\right| \cos \left(\delta_{p}-\delta_{q}-\theta_{p q}\right), \\
Q_{p}=Q_{s}+\sum_{q=1}^{\mathrm{nb}}\left|V_{p}\right|\left|V_{q}\right|\left|Y_{p q}\right| \sin \left(\delta_{p}-\delta_{q}-\theta_{p q}\right), \\
P_{s}=G_{s}\left|V_{p}\right|^{2}-\left|V_{p}\right|\left|E_{s}\right|\left|Y_{s}\right| \cos \left(\delta_{p}-\delta_{s}-\theta_{s}\right), \\
Q_{s}=-B_{s}\left|V_{p}\right|^{2}-\left|V_{p}\right|\left|E_{s}\right|\left|Y_{s}\right| \sin \left(\delta_{p}-\delta_{s}-\theta_{s}\right),
\end{gathered}
$$

where $\left|E_{s}\right|$ and $\delta_{s}$ are the magnitude and phase angle of STATCOM voltage source, respectively, and $\left|Y_{s}\right|$ and $\theta_{s}$ are the magnitude and phase angle of admittance in series with the STATCOM voltage source.

In this model the Jacobian matrix in Newton Raphson load flow method is extended by adding a new row and column to determine the two new variables $\left|E_{s}\right|$ and $\delta_{s}$ as in $[17,18]$. The initial value of STATCOM voltage is considered as 1.0 p.u and the control parameter of STATCOM in this model is $X_{s}$ and in turn varies with the real and reactive power injection/absorption of STATCOM with respect to the bus $p$ connected.

2.3. Unified Power Flow Controller. UPFC is a combined FACTS controller which has two Voltage Source Converters (VSC) connected back to back through a DC link. It is the most sophisticated FACTS device that works like a series and/or shunt compensator, voltage regulator, and phase shifter. In this paper, the power injection model of a UPFC device proposed by Noroozian in the year 1997 is used.

In this model, the series source converter is modeled as a voltage source in series with impedance $X_{s}$ as shown in Figure 3:

$$
\begin{aligned}
& \overline{V_{p}^{\prime}}=\overline{V_{s}}+\overline{V_{p}} \\
& \overline{V_{s}}=r \overline{V_{p}} e^{j \gamma},
\end{aligned}
$$

where $r$ is the magnitude and $\gamma$ is the phase angle of voltage injected by series converter of UPFC, and their value ranges are $0<r<r_{\max }$ and $0<\gamma<2 \pi$. The power injection model of UPFC including the shunt converter is depicted in Figure 4.

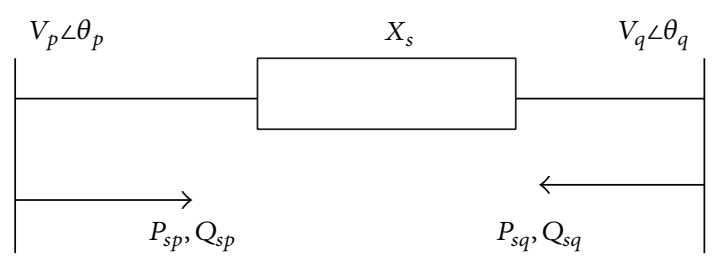

FIGURE 4: Power injection model of UPFC.

The injected real and reactive powers of UPFC at $p$ th and $q$ th bus as in [19] are as follows:

$$
\begin{aligned}
P_{s p} & =r b_{s} V_{p} V_{q} \sin \left(\theta_{p q}+\gamma\right), \\
Q_{s p} & =r b_{s} V_{p}^{2} \cos \gamma, \\
P_{s q} & =-r b_{s} V_{p} V_{q} \sin \left(\theta_{q p}+\gamma\right), \\
Q_{s q} & =-r b_{s} V_{p} V_{q} \cos \left(\theta_{p q}+\gamma\right),
\end{aligned}
$$

where $b_{s}=1 / X_{s}$.

This model can be easily implemented in Newton Raphson load flow method. If a UPFC is located between bus $p$ and bus $q$ in a power system, the bus admittance matrix of the system is modified by adding a reactance equivalent to $X_{s}$ between bus $p$ and bus $q$. The Jacobian matrix is modified by addition of appropriate powers as in [19]. The control parameters in this model are $r$ and $\gamma$.

\section{Problem Formulation}

The scope of this paper is to determine the optimal location of FACTS devices to obtain a maximum loadability in a power system with minimum total system real power loss and minimum installation cost of FACTS devices.

The objective function is

$$
F=\max (f 1)+\min (f 2)+\min (f 3),
$$

where

$f 1$ : Loadability of the system $(\lambda)$,

$$
f 2: P_{\text {Loss }}=\sum_{k=1}^{\mathrm{nl}} g_{i}\left[v_{s}^{2}+v_{r}^{2}-2 v_{s} v_{r} \cos \left(\delta_{s}-\delta_{r}\right)\right],
$$

and $\mathrm{nl}$ is the number of transmission lines; $g$ is the conductance of the transmission line branch:

$$
\text { f3: } \begin{aligned}
I C & =C * Q * 1000 \text { (US\$), } \\
C & =C_{\mathrm{TCSC}}+C_{\text {STATCOM }}+C_{\mathrm{UPFC}} .
\end{aligned}
$$

Based on Siemens AG Database, the cost functions for TCSC, STATCOM, and UPFC are

$$
\begin{aligned}
C_{\mathrm{UPFC}} & =0.0003(Q)^{2}-0.2691(Q)+188.22, \\
C_{\mathrm{TCSC}} & =0.0015(Q)^{2}-0.7130(Q)+153.75, \\
Q & =\left|Q_{2}-Q_{1}\right|, \\
C_{\text {STATCOM }} & =0.000375(Q)^{2}-0.3041(Q)+162.4,
\end{aligned}
$$


where $Q$ is the operating reactive range of FACTS controllers in MVAR; IC is the installation cost of FACTS devices in US\$; $Q_{1}$ and $Q_{2}$ are the reactive power flows in a line branch before and after placing FACTS device in MVAR. The above mentioned objectives are subject to the following constraints.

Equality Constraint: Power Flow Equation

$$
\begin{aligned}
& P_{G p}-P_{D p}-\sum_{r=1}^{\mathrm{nb}}\left|V_{p}\right|\left|V_{q}\right|\left|Y_{p q}\right| \cos \left(\theta_{p q}-\delta_{p}+\delta_{q}\right)=0, \\
& Q_{G p}-Q_{D p}-\sum_{r=1}^{\mathrm{nb}}\left|V_{p}\right|\left|V_{q}\right|\left|Y_{p q}\right| \sin \left(\theta_{p q}-\delta_{p}+\delta_{q}\right) \\
& \quad=0
\end{aligned}
$$

where nb is the total number of buses; $P_{G}$ and $Q_{G}$ are real and reactive power generations; $P_{D}$ and $Q_{D}$ are real and reactive power demands.

Inequality Constraints

$$
\begin{gathered}
P_{G p}^{\min } \leq P_{G p} \leq P_{G p}^{\max }, \\
Q_{G p}^{\min } \leq Q_{G p} \leq Q_{G p}^{\max }, \\
0.95 \leq V_{p} \leq 1.05 .
\end{gathered}
$$

FACTS Devices Constraints

$$
\begin{aligned}
-0.7 * X_{\text {line }} & \leq X_{c} \leq 0.2 * X_{\text {line }}, \\
0.5 & \leq X_{S} \leq 3.0 \\
0 & \leq r \leq 0.4 \\
0^{\circ} & \leq \gamma \leq 360^{\circ} .
\end{aligned}
$$

\section{Proposed Fuzzy DE Algorithm}

4.1. Differential Evolution Algorithm. DE is a populationbased stochastic optimization algorithm proposed by Storn and Price in the year 1996. It optimizes the real valued functions which are multidimensional, nonlinear, and discontinuous. The DE optimization is a multistage process with stages of initialization, mutation, recombination, and selection [20]. The implementations of various stages of $\mathrm{DE}$ in OPF are explained as follows.

(1) Set NG as Number of Generations, NP as Number of Populations, $n$ as Number of Vector Particles (control variables), minimum and maximum limits of each control variable, $S$ as Scaling Factor [0, 1.2], and CR as crossover constant $[0,1]$. The control parameters chosen in this work are generator's real power, generator's reactive power, generator's voltages, location of FACTS devices in the system, FACTS devices control parameters $\left(r_{c}, X_{s}, r, \gamma\right)$, and load factor $(\lambda)$ of the system.

(2) In this initialization step, a population of size $(\mathrm{NP} \times n)$ is randomly generated comprised of NP population vectors.
Each population vector $\left(X_{j} ; j=1: \mathrm{NP}\right)$ is comprised of $i$ control variables $\left(Y_{i} ; i=1: n\right)$ and each vector particle (Control variable) is randomly generated within its maximum and minimum limits using (14) and the number of population vectors are maintained throughout all generations. $X_{j}^{G}$ vector is otherwise called as parent vector or target vector:

$$
Y_{i}^{G}=Y_{i}^{\min }+\left(Y_{i}^{\max }-Y_{i}^{\min }\right) * \operatorname{rand}[0,1] .
$$

(3) Determine the fitness function (objective function) for each population vector $\left(X_{j}\right)$. In this paper the fitness functions are minimizing and maximizing the loadability, system real power loss, and installation cost of FACTS devices.

(4) Randomly choose any three population vectors from the population pool (say $X_{a}, X_{b}$, and $X_{c}$ ) and perform mutation operation using (15) to determine the mutated vector $\left(X_{M}\right)$. This operation helps in introducing new vectors in existing population. $S$ value is chosen in a way to have high convergence rate without trapping into local minima:

$$
\begin{aligned}
X_{M}^{G} & =X_{a}^{G}+S\left(X_{b}^{G} \sim X_{c}^{G}\right), \\
X_{a} & \neq X_{b} \neq X_{c} .
\end{aligned}
$$

(5) A random number $(\eta)$ is generated using binominal recombination and using this random number cross over operation is done to determine the trial vector $\left(X_{T}\right)$ as in

$$
X_{T}^{G}= \begin{cases}X_{M}^{G} ; & \text { if } \eta \leq \mathrm{CR} \\ X_{j}^{G} ; & \text { if } \eta>\mathrm{CR} .\end{cases}
$$

(6) New offsprings for next generation are produced by evaluating the fitness of trial vectors $\left(X_{T}\right)$ and original population vectors or target vectors $\left(X_{j}\right)$ using

$$
X_{j}^{(G+1)}= \begin{cases}X_{T}^{(G)} ; & \text { iff }\left(X_{T}^{G}\right) \leq f\left(X_{j}^{(G)}\right), \\ X_{j}^{(G)} ; & \text { iff }\left(X_{j}^{(G)}\right) \leq f\left(X_{T}^{(G)}\right) .\end{cases}
$$

(7) Repeat steps (4) to (6) until the stopping criteria are satisfied. In this paper Max Generation $=N G$ is chosen as the stopping criteria.

(8) Repeat steps (1) to (7) to determine the optimal solution (goal) for individual objectives. The goals for minimizing and maximizing individual objective are specified as $Z_{m i}$ and $Z_{n i}$.

4.2. Weighted Additive Fuzzy Goal Programming. Fuzzy linear programming was used by Zimmermann in solving multiobjective optimization problems in the year 1978 [21]. Tiwari in the year 1987 modified this approach as Weighted Additive Fuzzy Goal Programming. In this method, each objective function $\left(Z_{i}\right)$ of a multiobjective optimization problem is resolved to obtain its minimum $\left(Z_{m}\right)$ and maximum $\left(Z_{n}\right)$ goals individually satisfying all the constraints. All individual objectives are converted into fuzzy goals using 
their minimum and maximum goals as in (19) and (20), respectively [22]:

$$
\begin{aligned}
& \mu_{Z_{m}}(y) \\
& = \begin{cases}1 ; & Z_{m} \leq Z_{m}^{\min } \\
\frac{\left(Z_{m}^{\max }-Z_{m}(y)\right)}{\left(Z_{m}^{\max }-Z_{m}^{\min }\right)} ; & Z_{m}^{\min } \leq Z_{m}(y) \leq Z_{m}^{\max } \\
0 ; & Z_{m} \geq Z_{m}^{\max }\end{cases} \\
& \mu_{Z_{n}}(y) \begin{array}{ll}
1 ; & Z_{n} \geq Z_{n}^{\max } \\
\frac{\left(Z_{n}(y)-Z_{n}^{\min }\right)}{\left(Z_{n}^{\max }-Z_{n}^{\min }\right)} ; & Z_{n}^{\min } \leq Z_{n}(y) \leq Z_{n}^{\max } \\
0 ; & Z_{n} \leq Z_{n}^{\min }
\end{array} \\
& \quad n=p+1, p+2, \ldots, q .
\end{aligned}
$$

Fuzzy goals (FG) are combined together and WAFGP model is formulated as shown in (21) subjected to constraints as in (22) and solved to obtain optimal solutions. The optimal solutions depend on the weights $(W)$ assigned to each fuzzy goal:

$$
\operatorname{Max}\left(\sum_{i=1}^{q} W_{i} \mathrm{FG}_{i}\right)
$$

subject to

$$
\mathrm{FG}_{i} \leq \mu_{z_{i}}(y) ; \quad 0 \leq \mu_{Z i_{i}} \leq 1 ; 0 \leq W_{i} \leq 1 .
$$

4.3. Implementation of FDE (WAFGP with DE) Algorithm in $O P F$. FDE method consists of following steps.

(1) Set NG as Number of Generations, NP as Number of Populations, $n$ as Number of Vector particles (control variables), minimum and maximum limits of each control variable, $S$ as Scaling Factor $[0,1.2]$, and CR as crossover constant $[0,1]$.

(2) Determine the minimum $\left(Z_{m}\right)$ and maximium $\left(Z_{n}\right)$ goal for individual objective using $\mathrm{DE}$ algorithm. In this work, minimum loadability $\left(Z_{m 1}\right)$, maximum loadability $\left(Z_{n 1}\right)$, minimum system real loss $\left(Z_{m 2}\right)$, maximum system real loss $\left(Z_{n 2}\right)$, minimum installation cost of FACTS devices $\left(Z_{m 3}\right)$, and maximum installation cost of FACTS devices $\left(Z_{n 3}\right)$ are obtained using DE algorithm.

(3) Determine the fuzzy linear membership values for minimization goals $\left(Z_{m i}\right)$ and maximization goals $\left(Z_{n i}\right)$, where $i$ is the number of objectives ( $i=3$ ) using (19) and (20) for NP population vectors.

(4) Formulate the WAFGP model as in (21):

$$
\operatorname{Max}\left(W_{1} \mathrm{FG}_{1}+W_{2} \mathrm{FG}_{2}+W_{3} \mathrm{FG}_{3}\right) .
$$

(5) Determine the optimal weights $\left(W_{1}, W_{2}, W_{3}\right)$ using DE Algorithm for NP population vectors and find the optimal solution.
TABLE 1: Optimal location and rating of facts devices in NTPS-23 bus system.

\begin{tabular}{lccc}
\hline FACTS devices & $\begin{array}{c}\text { Best } \\
f 1\end{array}$ & $\begin{array}{c}\text { Best } \\
f 2\end{array}$ & $\begin{array}{c}\text { Best } \\
f 3\end{array}$ \\
\hline TCSC & & & \\
$\quad$ Location & $\# 1-2$ & $\# 1-5$ & $\# 1-2$ \\
$\quad r_{c}$ & -0.4828 & -0.1910 & -0.2451 \\
STATCOM & & & \\
$\quad$ Location & Bus 7 & Bus 8 & Bus 7 \\
$\quad X_{s}$ & 2.6782 & 2.8615 & 2.2981 \\
UPFC & & & \\
Location & $\# 3-13$ & $\# 3-13$ & $\# 3-13$ \\
$r$ & 0.2410 & 0.0238 & 0.1759 \\
$\gamma$ & 297.1062 & 293.4171 & 333.3421 \\
\hline
\end{tabular}

\# denotes the transmission line branch of NTPS 23 bus system.

(6) Repeat steps (3) to (5) for NG number of generations.

(7) Obtain the best optimal maximum loadability of the system with minimum system real power loss and minimum installation cost of FACTS devices.

\section{Case Studies and Discussions}

The proposed combined approach of WAFGP and DE algorithm for solving multiobjective problem is tested on Indian utility Neyveli Thermal Power Station (NTPS) 23 bus system [23] using Matlab 7.5. This practical thermal utility system has one slack bus, 3 generator buses, 19 load buses, and 22 transmission lines. The load factor is varied from 1.0 to 1.5 allowing a $50 \%$ increase in real power loading. The values chosen for NP and NG are 100 and 200, respectively, in DE and in RCGA. In DE algorithm the value chosen for SF is 0.6 and for $\mathrm{CF}$ is 0.7 .

The optimal locations of TCSC, STATCOM, and UPFC with their rated values are obtained to achieve the best optimal results for the objective functions $f 1, f 2$, and $f 3$ individually using DE and RCGA. $f 1$ is the objective dealing with maximization of the load factor of the system, $f 2$ deals with the minimization of system real loss, and $f 3$ deals with the minimum installation cost of the FACTS devices. The optimal rated control values of FACTS devices along with their location using DE algorithm are depicted in Table 1 and the comparative results of best optimal solutions for various individual objectives with DE and RCGA are shown in Figures 5, 6, and 7.

The comparison results in Figures 5, 6, and 7 demonstrate that DE algorithm performs better than GA and shows the potential of individual and combined FACTS devices in achieving the individual objectives. In the next level TCSC, STATCOM, and UPFC are used simultaneously to achieve the minimum and maximum optimal goals individually and the results are displayed in Table 2.

Results in Table 2 show that when increasing the loadability of the system is considered as the only objective, the real power loss in the system is very high. When minimizing real 
TABLE 2: Best pareto optimal solutions for combined facts devices in NTPS-23 bus system using DE.

\begin{tabular}{|c|c|c|c|c|c|c|}
\hline & \multicolumn{2}{|c|}{$f 1(\%)$} & \multicolumn{2}{|c|}{$f 2(\times 100 \mathrm{Mw})$} & \multicolumn{2}{|c|}{$f 3\left(\times 10^{6}\right.$ US\$ $)$} \\
\hline & $\operatorname{Min}\left(Z_{m 1}\right)$ & $\operatorname{Max}\left(Z_{n 1}\right)$ & $\operatorname{Min}\left(Z_{m 2}\right)$ & $\operatorname{Max}\left(Z_{n 2}\right)$ & $\operatorname{Min}\left(Z_{m 3}\right)$ & $\begin{array}{c}\operatorname{Max} \\
\left(Z_{n 3}\right) \\
\end{array}$ \\
\hline Location of TCSC & \# 3-1 & $\# 1-2$ & \# 3-1 & \# 1-2 & $\# 1-2$ & \# 1-5 \\
\hline Location of STATCOM & Bus 8 & Bus 9 & Bus 6 & Bus 7 & Bus 6 & Bus 9 \\
\hline Location of UPFC & $\# 2-4$ & \# 3-13 & \# 3-13 & $\# 2-4$ & $\# 2-4$ & \# 3-1 \\
\hline$r_{c}$ & -0.165 & -0.565 & -0.565 & -0.691 & -0.024 & -0.061 \\
\hline$X_{s}$ & 2.573 & 1.423 & 2.249 & 0.925 & 0.723 & 2.672 \\
\hline$r$ & 0.287 & 0.009 & 0.299 & 0.003 & 0.039 & 0.323 \\
\hline$\gamma$ & 300.553 & 345.110 & 280.607 & 342.548 & 274.248 & 291.103 \\
\hline$f 1(\%)$ & 100 & 141 & 100 & 139 & 100 & 140 \\
\hline$f 2(\times 100 \mathrm{Mw})$ & 0.150 & 0.320 & 0.137 & 0.280 & 0.145 & 0.296 \\
\hline$f 3\left(\times 10^{6}\right.$ US\$) & 1.4123 & 22.172 & 1.2972 & 20.272 & 1.2859 & 19.017 \\
\hline
\end{tabular}

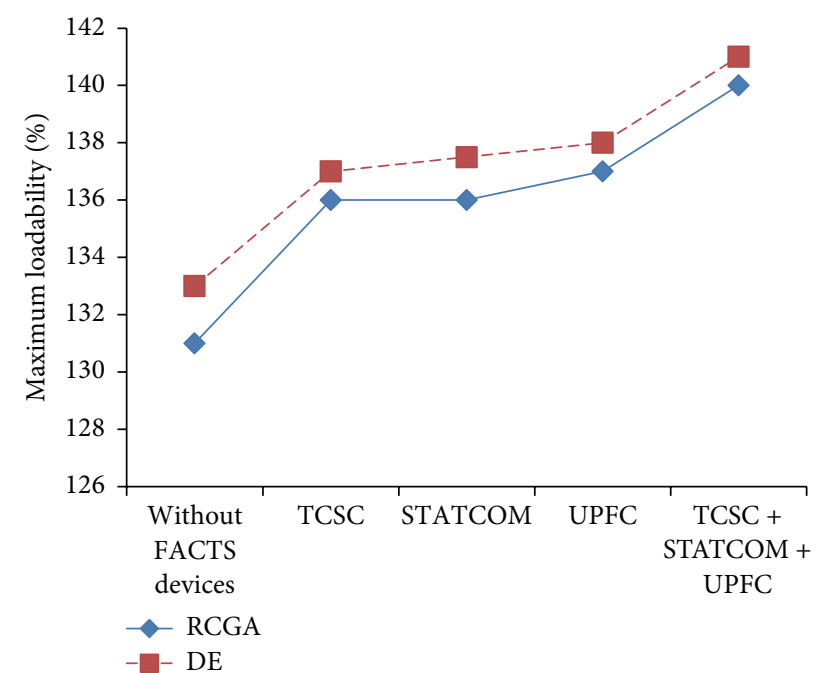

FIGURE 5: Comparison results of maximum loadability for NTPS23 bus system.

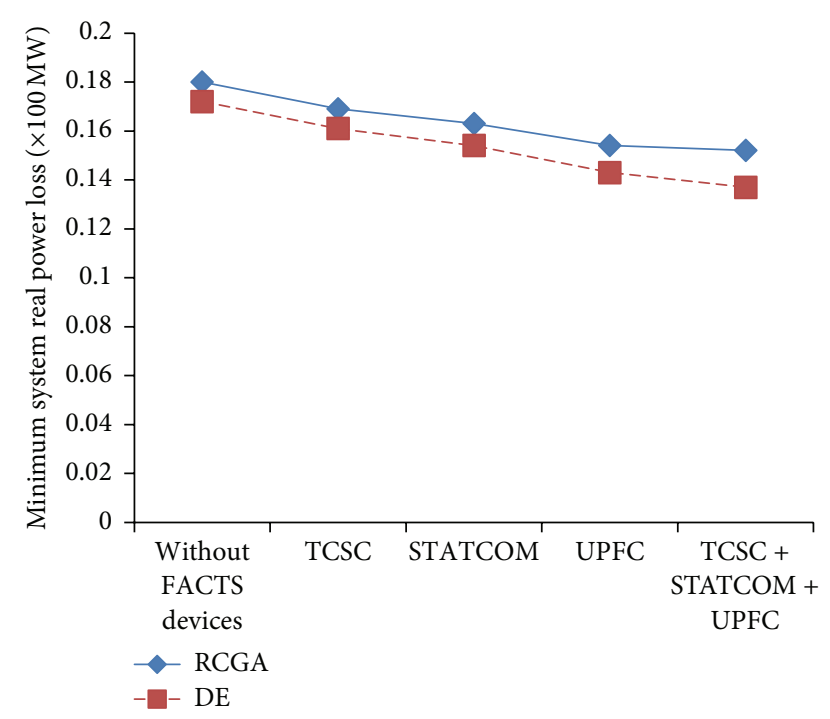

Figure 6: Comparison results of minimum real power loss for NTPS23 bus system.
TABLE 3: Best optimal solutions using FDE for NTPS23 bus system.

\begin{tabular}{lccc}
\hline Location of TCSC & $\# 3-13$ & $r_{c}$ & -0.5101 \\
Location of STATCOM & Bus 7 & $X_{s}$ & 2.8364 \\
Location of UPFC & $\# 2-4$ & $r$ & 0.1880 \\
Weight $W 1$ & & $\gamma$ & 279.0781 \\
Weight $W 2$ & 0.5011 & $f 1(\%)$ & 139 \\
Weight $W 3$ & 0.1465 & $f 2(\times 100 \mathrm{Mw})$ & 0.204 \\
\hline
\end{tabular}

TABLE 4: Comparison results for installation cost of facts devices for NTPS23 bus system.

\begin{tabular}{lcc}
\hline Optimal $\lambda(\%)$ & \multicolumn{2}{c}{ Optimal IC for FACTS devices $\left(\times 10^{6}\right.$ US\$) } \\
$\begin{array}{c}\text { With WAFGP optimal } \\
\text { weights (FDE) }\end{array}$ & Without weights \\
\hline 139 & 6.5779 & 6.9982 \\
\hline
\end{tabular}

power loss or installation cost of FACTS devices is considered as the only objective, the loadability of the system is low. This result highlights the need for balancing the multiple objectives rather than focusing on a single objective.

To achieve this balance, DE based WAFGP multiobjective technique is used. This multiobjective technique aims to achieve the optimal results for maximum loadability, minimum real power loss, and minimum installation cost of FACTS devices by obtaining the optimal location and control parameter settings for TCSC, STATCOM, and UPFC combination.

The minimum and maximum goals of individual objectives are converted into fuzzy numbers using fuzzy membership functions as in (19) and (20). WAFGP model is framed as in (21) and DE algorithm is used to optimize the weights. The final optimal results are depicted in Table 3.

The results in Table 3 show that different objectives are achieved in a balanced manner than achieving one objective at the cost of other objectives as in Table 2. To show the merits of optimal weights, the installation cost of combined FACTS devices computed using WAFGP is compared against FGP 


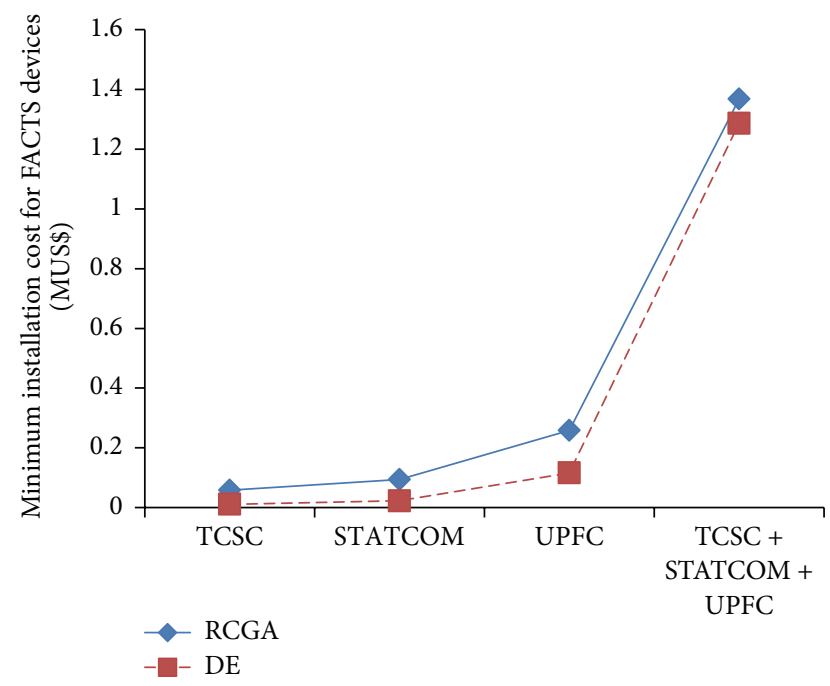

Figure 7: Comparison results of minimum installation cost of FACTS devices for NTPS23 bus system.

approach and the results are shown in Table 4 . The results show that, for the same loadability condition, installation cost of FACTS devices obtained by WAFGP approach is significantly lower than the installation cost of FACTS devices obtained by FGP.

From the results of Tables 3 and 4, it is concluded that DE based WAFGP approach provides an optimal solution for a multiobjective power flow problems and can be implemented for any higher order systems with any number of objectives.

\section{Conclusion}

In this paper, analysis performed on the Indian utility NTPS 23 bus system demonstrates that the best optimal solution for single objectives are obtained by optimal placing and configuration of TCSC, STATCOM, and UPFC devices using DE algorithm when compared to that of RCGA. The results also indicate that when multiple objectives have to be optimized, the focus on a single objective has severe negative impact on other objectives. To consider multiple objectives simultaneously, WAFGP technique is used. Since the weights in WAFGP have a significant importance in deciding the optimal solution, DE algorithm is used for optimizing the weights. The single optimal solution for multiobjective OPF by the DE based WAFGP algorithm clearly indicates that each objective obtains its optimal solution without compromising other objectives. Thus, this algorithm provides a balance in optimizing multiple objectives and thereby preserves the uniqueness of each individual objective. Further, comparison of results with that of DE based FGP shows that the use of WAFGP with optimized weights results in minimum installation cost of FACTS devices and thereby better economical solution.

\section{Conflict of Interests}

The authors declare that there is no conflict of interests regarding the publication of this paper.

\section{References}

[1] N. G. Hingorani, "Flexible AC transmission," IEEE Spectrum, vol. 30, no. 4, pp. 40-45, 1993.

[2] M. Tripathy and S. Mishra, "Bacteria foraging-based solution to optimize both real power loss and voltage stability limit," IEEE Transactions on Power Systems, vol. 22, no. 1, pp. 240-248, 2007.

[3] M. Saravanan, S. M. R. Slochanal, P. Venkatesh, and J. P. S. Abraham, "Application of particle swarm optimization technique for optimal location of FACTS devices considering cost of installation and system loadability," Electric Power Systems Research, vol. 77, no. 3-4, pp. 276-283, 2007.

[4] J. Baskaran and V. Palanisamy, "Optimal location of FACTS devices in a power system solved by a hybrid approach," Nonlinear Analysis: Theory, Methods \& Applications, vol. 65, no. 11, pp. 2094-2102, 2006.

[5] S. Shojaeian, E. S. Naeeni, M. Dolatshahi, and H. Khani, "A PSODP based method to determination of the optimal number, location, and size of FACTS devices in power systems," Advances in Electrical and Computer Engineering, vol. 14, no. 1, pp. 109-114, 2014.

[6] W. Ongsakul and P. Bhasaputra, "Optimal power flow with FACTS devices by hybrid TS/SA approach," International Journal of Electrical Power \& Energy Systems, vol. 24, no. 10, pp. 851857, 2002.

[7] L. A. Zadeh, "Fuzzy sets," Information and Control, vol. 8, no. 3, pp. 338-353, 1965.

[8] R. Narasimhan, "Goal programming in a fuzzy environment," Decision Sciences, vol. 11, no. 2, pp. 325-336, 1980.

[9] R. N. Tiwari, S. Dharmar, and J. R. Rao, "Fuzzy goal programming - an additive model," Fuzzy Sets and Systems, vol. 24, no. 1, pp. 27-34, 1987.

[10] W. D. Rosehart, C. A. Cañizares, and V. H. Quintana, "Multiobjective optimal power flows to evaluate voltage security costs in power networks," IEEE Transactions on Power Systems, vol. 18, no. 2, pp. 578-587, 2003.

[11] J. Hazra and A. K. Sinha, "A multi-objective optimal power flow using particle swarm optimization," European Transactions on Electrical Power, vol. 21, no. 1, pp. 1028-1045, 2011.

[12] R.-H. Liang, S.-R. Tsai, Y.-T. Chen, and W.-T. Tseng, "Optimal power flow by a fuzzy based hybrid particle swarm optimization approach," Electric Power Systems Research, vol. 81, no. 7, pp. 1466-1474, 2011.

[13] S. Sivasubramani and K. S. Swarup, "Multi-objective harmony search algorithm for optimal power flow problem," International Journal of Electrical Power \& Energy Systems, vol. 33, no. 3, pp. 745-752, 2011.

[14] X. H. He, W. Wang, Y. N. Wang, J. Kong, J. Geng, and S. B. Fan, "Fuzzy optimal power flow with multi-objective based on artificial bee colony algorithm in power system," Applied Mechanics and Materials, vol. 448-453, pp. 2473-2477, 2014.

[15] R. Azizipanah-Abarghooee, M. R. Narimani, B. BahmaniFirouzi, and T. Niknam, "Modified shuffled frog leaping algorithm for multi-objective optimal power flow with FACTS devices," Journal of Intelligent and Fuzzy Systems, vol. 26, no. 2, pp. 681-692, 2014. 
[16] S. Sreejith, K. Chandrasekaran, and S. P. Simon, "Application of touring ant colony optimization technique for optimal power flow incorporating thyristor controlled series compensator," in Proceedings of the IEEE Region 10 Conference (TENCON '09), pp. 1-6, Singapore, January 2009.

[17] M. O. Hassan, S. J. Cheng, and Z. A. Zakaria, "Steady-state modeling of static synchronous compensator and thyristor controlled series compensator for power flow analysis," Information Technology Journal, vol. 8, no. 3, pp. 347-353, 2009.

[18] R. Vanitha, J. Baskaran, and M. Sudhakaran, "Multi objective optimal power flow with STATCOM using DE in WAFGP," Indian Journal of Science and Technology, vol. 8, no. 2, pp. 191198, 2015.

[19] M. Noroozian, L. Ängquist, M. Ghandhari, and G. Andersson, "Use of UPFC for optimal power flow control," IEEE Transactions on Power Delivery, vol. 12, no. 4, pp. 1629-1634, 1997.

[20] R. Storn and K. Price, "Differential evolution-a simple and efficient heuristic for global optimization over continuous spaces," Journal of Global Optimization, vol. 11, no. 4, pp. 341359, 1997.

[21] H.-J. Zimmermann, "Fuzzy programming and linear programming with several objective functions," Fuzzy Sets and Systems, vol. 1, no. 1, pp. 45-55, 1978.

[22] A. Amid, S. H. Ghodsypour, and C. O’Brien, "Fuzzy multiobjective linear model for supplier selection in a supply chain," International Journal of Production Economics, vol. 104, no. 2, pp. 394-407, 2006.

[23] P. Ajay-D-Vimal Raj, Performance evaluation of swarm intelligence based power system optimization strategies [Ph.D. dissertation], Department of Electronics and Communication Engineering, Pondicherry University, Pondicherry, India, 2008. 


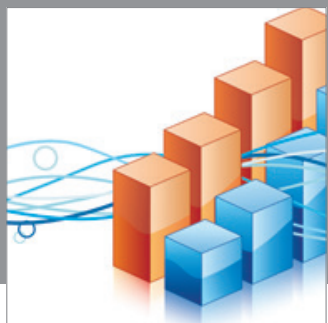

Advances in

Operations Research

mansans

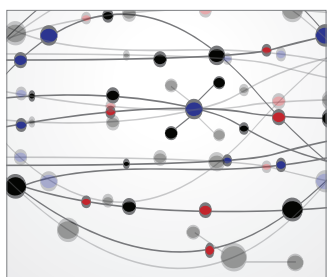

The Scientific World Journal
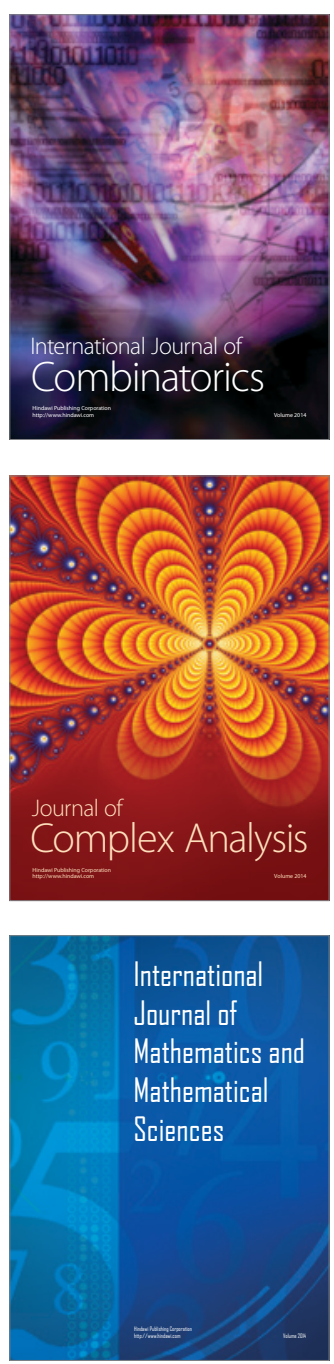
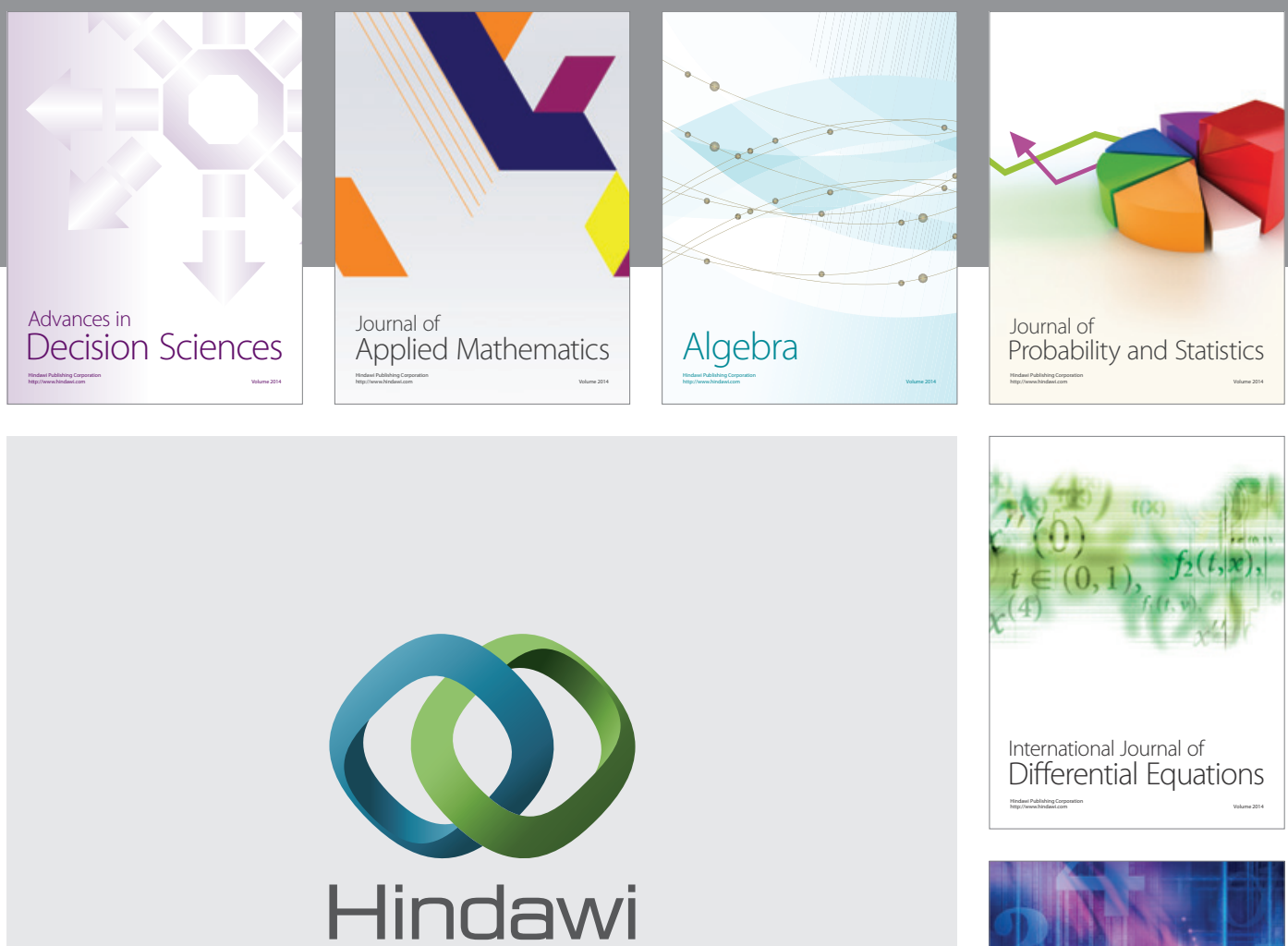

Submit your manuscripts at http://www.hindawi.com
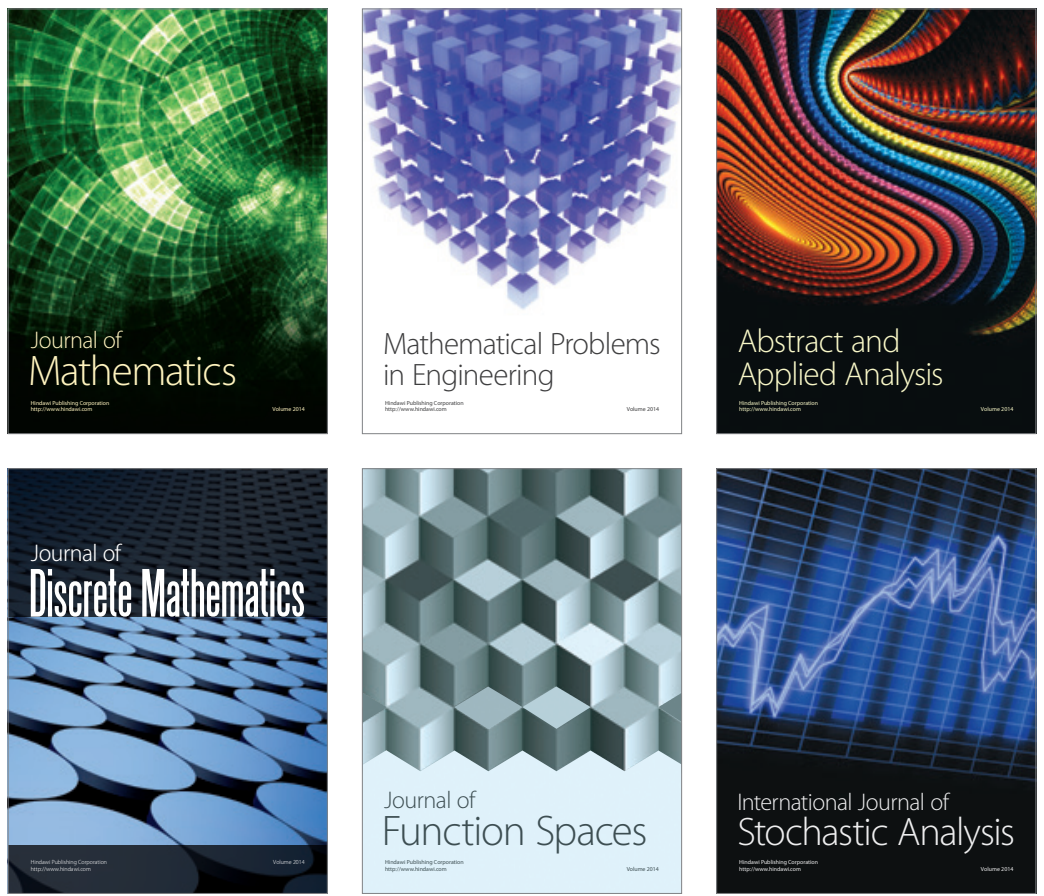

Journal of

Function Spaces

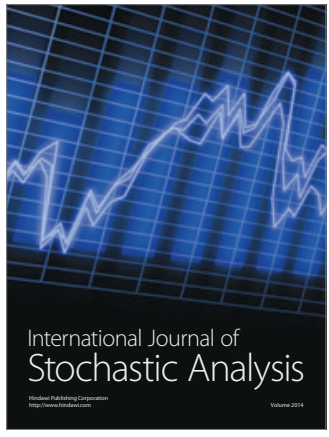

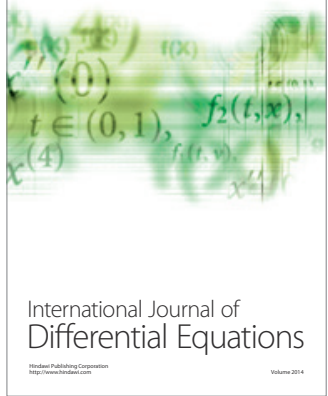
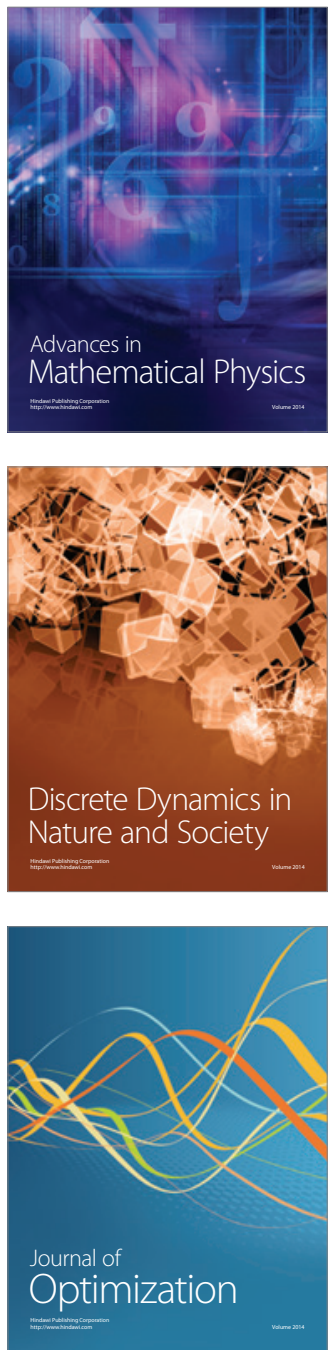